\title{
Crystal Structure of a Biosynthetic Sulfo-hirudin Complexed to Thrombin
}

\author{
Chang C. Liu, Eric Brustad, Wenshe Liu, and Peter G. Schultz \\ Department of Chemistry and the Skaggs Institute for Chemical Biology, The Scripps Research \\ Institute, 10550 North Torrey Pines Road, La Jolla, California 92037, E-mail: schultz@scripps.edu, \\ wsliu@scripps.edu
}

The leech derived protein hirudin is the most potent naturally occurring direct thrombin inhibitor (DTI) known and is used clinically as an anticoagulant. ${ }^{1,2}$ The natural form of hirudin (sulfo-hirudin) exhibits a $\mathrm{K}_{i}$ towards thrombin of approximately $25 \mathrm{fM}$, and the therapeutic form of the protein generated recombinantly in $E$. coli or yeast exhibits a $\mathrm{K}_{i}$ of approximately $300 \mathrm{fM}^{3,4}$ The difference in activity between the natural and recombinant versions of hirudin results from a sulfated tyrosine in the natural version, which enhances the binding interaction between the anionic $\mathrm{C}$-terminus of hirudin and exosite $\mathrm{I}$ of thrombin. ${ }^{3,5}$ Because tyrosine sulfation is a post-translational modification found only in higher eukaryotes, recombinant hirudin (desulfo-hirudin) does not undergo this functionally important modification, resulting in a less potent DTI anticoagulant.

Although the effects of sulfation on thrombin inhibition by hirudin have been studied extensively, $, 4,4,6,7$ at the structural level, the story remains incomplete. Structures of several complexes of desulfo-hirudin with thrombin as well as of the sulfated hirudin-derived peptides with thrombin have been solved, ${ }^{5,8-11}$ but there is currently no structure of sulfo-hirudin complexed with thrombin. The lack of such a structure owes to the fact that natural hirudin is extracted from leech heads in very low yields, a process prohibitively inefficient for crystallographic screens. ${ }^{2} \mathrm{We}$ recently reported an approach to the biosynthesis of selectively sulfated proteins in $E$. coli, which makes use of an orthogonal aminoacyl-tRNA synthetase/ tRNA pair specific for sulfotyrosine that incorporates this amino acid into proteins in response to the amber nonsense codon. ${ }^{4}$ Using this method, sulfo-hirudin was recombinantly produced in sufficient quantities for crystallization $(\sim 5 \mathrm{mg} / \mathrm{L})$. Here, we report the $1.84 \AA ̊$ resolution Xray crystal structure of sulfo-hirudin complexed to human $\alpha$-thrombin. This complex reveals the detailed structural basis for the increase in affinity for thrombin by hirudin upon sulfation. We also observe a previously unidentified divalent metal binding site between the heavy and light chains of thrombin that may modulate thrombin stability and activity.

The backbone conformation of sulfo-hirudin is almost identical to that of desulfo-hirudin ${ }^{8}$ with an rms deviation of $1.08 \AA$, suggesting that sulfation does not cause any significant conformational changes to the polypeptide backbone. The sulfate group, however, does mediate several important interactions between thrombin and hirudin. Three lysines of thrombin were proposed as potential interaction partners with the sulfotyrosine of hirudin (hTys63) on the basis of the original crystal structure of the desulfo-hirudin/thrombin complex. 5 Our structure shows that Lys81 of thrombin (t-Lys81) directly interacts with the sulfate of h-Tys63 at a distance of $3.1 \AA$, creating a strong salt bridge (Figure 1A). In structures of desulfohirudin and desulfo-hirudin fragments complexed to thrombin, $8,9,12$ t-Lys 81 is oriented away from the analogous Tyr63, indicating that sulfation forces a change in the t-Lys81 side-chain 
conformation. This salt bridge interaction is consistent with mutagenesis data on full hirudin, 13 although previous structures in which synthetic sulfated C-terminal peptide fragments (hirugens) were bound to thrombin do not reveal a salt bridge. In these structures, the t-Lys81 orients away from the sulfate, ${ }^{10,14-16}$ is too distant, ${ }^{17}$ or is disordered. ${ }^{11}$ Thus it appears that full-length sulfo-hirudin is required to observe this interaction.

Tyr76 of thrombin (t-Tyr76) has also been proposed as a residue responsible for sulfotyrosine binding. ${ }^{9}$ This is confirmed by our structure, which shows a hydrogen bond between the phenolic -OH of t-Tyr76 and an oxygen of the h-Tys63 sulfate (Figure 1A) - previous structures in which hirugens are bound to thrombin reveal a similar interaction. The same oxygen atom also interacts with a water molecule, which mediates an extended hydrogen bond network that involves another oxygen atom of the sulfate, a backbone amide of thrombin Asn78, and a backbone carbonyl group of thrombin Glu80. This is distinct from the hydrogen bond networks found in structures of the hirugen/thrombin complex. ${ }^{10,11}$ The hydrogen bond network and the strong salt bridge observed in the sulfo-hirudin/thrombin complex collectively involve interactions with all three oxygens of the sulfate group, thus explaining the effect of sulfation on thrombin inhibition.

The sulfo-hirudin/thrombin structure also reveals two metal ion binding sites in thrombin. The first is a known sodium ion site composed of the backbone carbonyl groups of residues $\operatorname{Arg} 221 \mathrm{~A}$ and Lys224 of thrombin. $\mathrm{Na}^{+}$allosterically regulates thrombin activity such that sodium binding results in the high activity fast form of the enzyme. Because hirudin inhibits the fast form of thrombin, $\mathrm{Na}^{+}$and hirudin binding are observed in concert. ${ }^{12,18}$ Unexpectedly, we found $\mathrm{Ni}^{2+}$ in a second metal ion binding site defined by residues Asp1A and Lys9 of thrombin's light chain and residue His119 of thrombin's heavy chain (Figure 1B); three water molecules complete the coordination sphere. This $\mathrm{Ni}^{2+}$ bridges the light chain and the heavy chain of $\alpha$-thrombin, which are also connected by a disulfide bond.

We have not found this divalent cation binding site in previous structures nor in biochemical studies. However, the $\sim 100 \%$ occupancy of $\mathrm{Ni}^{2+}$ in our structure in the presence of $<10 \mathrm{mM}$ $\mathrm{NiCl}_{2}$ and its identical coordination geometry to those of $\mathrm{Ca}^{2+}$ and $\mathrm{Mg}^{2+}$ ions (which mediate the coagulation response in the low millimolar range in serum), ${ }^{19}$ suggest that the cation binding site may not be a crystal artifact. In addition, a homozygous deletion of the $\mathrm{Ni}^{2+}$ ligand Lys9 (light chain) was recently identified in patients with severe prothrombin deficiency and hemorrhagic diathesis. ${ }^{20,21}$ Subsequent biochemical studies of this $\alpha$-thrombin mutant showed it to have decreased stability; weakened association between the light chain and the heavy chain; and perturbed activity, specificity, and signaling. ${ }^{20,22}$ It was proposed that deletion of Lys9 results in the loss of a salt-bridging interaction between Asp1A and Lys9 and the attenuation of ionic interactions between the two thrombin subunits, leading to the observed changes in stability, conformation, and activity. 20,21 In light of our data, we hypothesize that a divalent cation serves a structural role by stabilizing the light chain conformation and mediating additional interactions between the light and heavy chains. Furthermore, since the Lys9 deletion mutant results in an allosteric perturbation of thrombin's active site, metal binding at this site could modulate thrombin activity, although we do not dismiss the possibility that the Lys9 deletion causes a significant structural perturbation, complicating its observed effects.

The study of post-translational modifications such as sulfation presents a significant challenge since almost all modifications are inaccessible in E. coli and control over post-translational modification selectivity and efficiency is often lacking in yeast, insect, and mammalian expression systems. The ability to genetically incorporate unnatural amino acids into proteins provides a solution to this problem. In this case, determination of the X-ray crystal structure of the sulfo-hirudin/thrombin complex revealed key interactions between sulfo-hirudin and 
thrombin mediated by sulfotyrosine, including a previously unidentified salt bridge and an extended hydrogen bond network. A divalent cation binding site at the interface of the two $\alpha$ thrombin subunits was also identified and we are currently conducting biochemical and mutagenesis studies to dissect the role of metal at this site.

\section{Supplementary Material}

Refer to Web version on PubMed Central for supplementary material.

\section{Acknowledgements}

The work in this communication is based on experiments conducted at beamline 5.0.1 and 5.0.3 of the Advanced Light Source (ALS). The ALS is supported by the director, Office of Science, Office of Basic Energy Sciences, and the Material Sciences Division of the US Department of Energy under contract DEAC03-765F00098 at the Lawrence Berkeley National Laboratory. We thank Glen Spraggon for assistance with data collection. C.C.L. is supported by predoctoral fellowships from the Fannie and John Hertz Foundation and the National Science Foundation. This research was supported by the US National Institutes of Health (GM62159). This is The Scripps Research Institute manuscript no. 18930.

\section{References}

1. Markwardt F. Semin Thromb Hemost 2002;28:405-14. [PubMed: 12420235]

2. Sohn JH, Kang HA, Rao KJ, Kim CH, Choi ES, Chung BH, Rhee SK. Appl Microbiol Biotechnol 2001;57:606-13. [PubMed: 11778867]

3. Stone SR, Hofsteenge J. Biochemistry 1986;25:4622-4628. [PubMed: 3768302]

4. Liu CC, Schultz PG. Nat Biotechnol 2006;24:1436-40. [PubMed: 17072302]

5. Rydel TJ, Ravichandran KG, Tulinsky A, Bode W, Huber R, Roitsch C, Fenton JW 2nd. Science 1990;249:277-80. [PubMed: 2374926]

6. Braun PJ, Dennis S, Hofsteenge J, Stone SR. Biochemistry 1988;27:6517-22. [PubMed: 3146347]

7. Komatsu Y, Misawa S, Sukesada A, Ohba Y, Hayashi H. Biochem Biophys Res Commun 1993;196:773-9. [PubMed: 8240353]

8. Rydel TJ, Tulinsky A, Bode W, Huber R. J Mol Biol 1991;221:583-601. [PubMed: 1920434]

9. Grutter MG, Priestle JP, Rahuel J, Grossenbacher H, Bode W, Hofsteenge J, Stone SR. Embo J 1990;9:2361-5. [PubMed: 2369893]

10. Skrzypczak-Jankun E, Carperos VE, Ravichandran KG, Tulinsky A, Westbrook M, Maraganore JM. J Mol Biol 1991;221:1379-93. [PubMed: 1942057]

11. Priestle JP, Rahuel J, Rink H, Tones M, Grutter MG. Protein Sci 1993;2:1630-42. [PubMed: 8251938]

12. Zhang E, Tulinsky A. Biophys Chem 1997;63:185-200. [PubMed: 9108691]

13. Betz A, Hofsteenge J, Stone SR. Biochemistry 1991;30:9848-53. [PubMed: 1911777]

14. Nardini M, Pesce A, Rizzi M, Casale E, Ferraccioli R, Balliano G, Milla P, Ascenzi P, Bolognesi M. J Mol Biol 1996;258:851-9. [PubMed: 8637015]

15. Hauel NH, Nar H, Priepke H, Ries U, Stassen JM, Wienen W. J Med Chem 2002;45:1757-66. [PubMed: 11960487]

16. Chen Z, Li Y, Mulichak AM, Lewis SD, Shafer JA. Arch Biochem Biophys 1995;322:198-203. [PubMed: 7574675]

17. Skordalakes E, Dodson GG, Green DS, Goodwin CA, Scully MF, Hudson HR, Kakkar VV, Deadman JJ. J Mol Biol 2001;311:549-55. [PubMed: 11493008]

18. Mengwasser KE, Bush LA, Shih P, Cantwell AM, Di Cera E. J Biol Chem 2005;280:26997-7003. [PubMed: 15923186]

19. Harrison, TR. Harrison's Principles of Internal Medicine. 16. McGraw-Hill Professional; 2004.

20. De Cristofaro R, Akhavan S, Altomare C, Carotti A, Peyvandi F, Mannucci PM. J Biol Chem 2004;279:13035-43. [PubMed: 14722067]

21. Akhavan S, Mannucci PM, Lak M, Mancuso G, Mazzucconi MG, Rocino A, Jenkins PV, Perkins SJ. Thromb Haemost 2000;84:989-97. [PubMed: 11154146] 
22. De Cristofaro R, Carotti A, Akhavan S, Palla R, Peyvandi F, Altomare C, Mannucci PM. Febs J 2006;273:159-69. [PubMed: 16367756] 


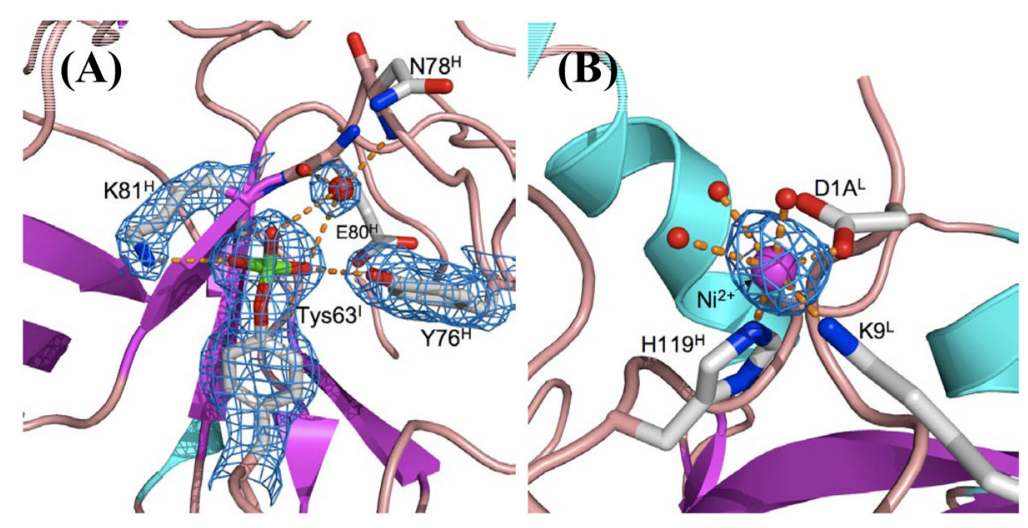

Figure 1.

(A) Structure of sulfotyrosine (Tys) and amino acid residues that directly or indirectly interact with the sulfate group of Tys in the sulfo-hirudin/thrombin complex. The $\mathrm{F}_{\mathrm{o}}-\mathrm{F}_{\mathrm{c}}$ electron density map covering Tys63 ${ }^{\mathrm{I}}, \mathrm{K} 81^{\mathrm{H}}, \mathrm{Y}_{76}{ }^{\mathrm{H}}$, and a water molecule was contoured at $1 \sigma$. Dashed lines shown in orange are hydrogen bonds. (B) $\mathrm{Ni}^{2+}$ binding site of thrombin. The $\mathrm{F}_{\mathrm{o}}-\mathrm{F}_{\mathrm{c}}$ electron density map covering $\mathrm{Ni}^{2+}$ was contoured at $5 \sigma$. Dashed lines are coordination interactions between $\mathrm{Ni}^{2+}$ and surrounding ligands. Backbone carbons in (A) and (B) are presented in the same color as that of the corresponding secondary structure (helices in cyan, strands in purple, and loops in pink). The side chains of amino acid residues are colored in red for oxygen, light gray for carbon, blue for nitrogen, and green for sulfur. Water molecules are represented as balls and colored in red. The superscripts of amino acid labels represent chain identification: $\mathrm{H}$ is the heavy chain of thrombin; $\mathrm{L}$ is the light chain of thrombin and $\mathrm{I}$ is the inhibitor sulfohirudin. Thrombin residues are labeled according to the chymotrypsinogen numbering scheme. (See Table 1 for crystal statistics.) 
Table 1

Data Collection and Refinement Statistics

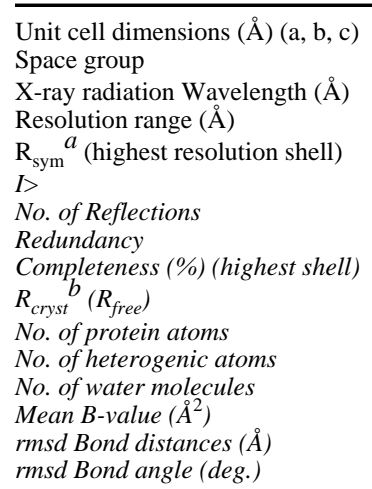

X-ray radiation Wavelength $(\AA)$

Resolution range $(\AA)$

$\mathrm{R}_{\mathrm{sym}}{ }^{a}$ (highest resolution shell)

I>

No. of Reflections

Redundancy

Completeness (\%) (highest shell)

$R_{\text {cryst }}^{b}\left(R_{\text {free }}\right)$

No. of protein atoms

No. of heterogenic atoms

No. of water molecules

Mean B-value $\left(\AA^{2}\right)$

rmsd Bond distances $(\AA)$

rmsd Bond angle (deg.)

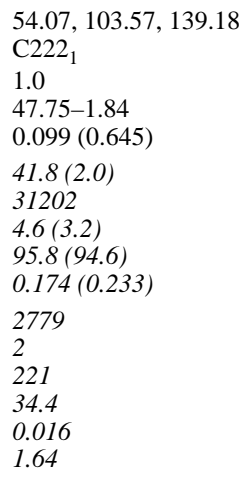

1.0

47.75-1.84

$0.099(0.645)$

$41.8(2.0)$

31202

$4.6(3.2)$

$95.8(94.6)$

$0.174(0.233)$

2779

2

221

0.016

1.64

${ }^{a} \mathrm{R}_{\mathrm{sym}}=\Sigma \Sigma_{\mathrm{j}}\left|\mathrm{I}_{\mathrm{j}}(\mathrm{hkl})-<\mathrm{I}(\mathrm{hkl})>\right| / \Sigma \Sigma_{\mathrm{j}}|\mathrm{I}(\mathrm{hkl})|$, where $\mathrm{I}_{\mathrm{j}}$ is the measured intensity of reflection $\mathrm{j}$ and is the mean intensity over $\mathrm{j}$ reflections.

${ }^{b} \mathrm{R}_{\text {cryst }}=\Sigma|| \mathrm{F}_{\mathrm{obs}}(\mathrm{hkl})|-| \mathrm{F}_{\text {calc }}(\mathrm{hkl}) \| / \Sigma\left|\mathrm{F}_{\mathrm{obs}}(\mathrm{hkl})\right|$, where $\mathrm{F}_{\mathrm{obs}}$ and $\mathrm{F}_{\text {calc }}$ are observed and calculated structure factors, respectively. No $\sigma$-cutoff was applied. 